\title{
Europäische Diskriminierungsverbote und Privatrecht
} Unionsrechtliche Vorgaben und Sanktionen

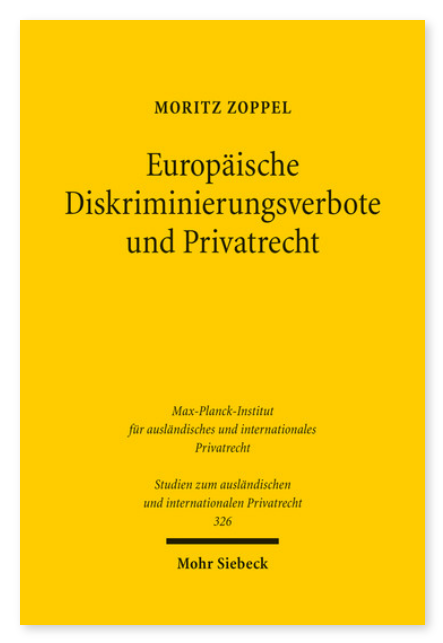

2015. XIV, 221 Seiten. StudIPR 326

ISBN 978-3-16-153312-9

DOI 10.1628/978-3-16-153312-9

eBook PDF 74,00€

ISBN 978-3-16-153298-6

fadengeheftete Broschur 74,00€
Der Einsatz der Europäischen Union auf dem Gebiet des privatrechtlichen Diskriminierungsschutzes hat in den letzten Jahren für viel Aufsehen gesorgt. Lassen sich Diskriminierungsverbote mit dem Grundsatz der Vertragsfreiheit vereinbaren oder ist der Unionsgesetzgeber zu weit gegangen? Moritz Zoppel nimmt die emotional geführte Diskussion zum Anlass um gesellschaftspolitische Diskriminierungsverbote im Privatrecht zu untersuchen. Die Arbeit gliedert sich dazu in vier Abschnitte.

Zunächst überprüft der Autor die Verbote der rassistischen und sexistischen Diskriminierung auf ihre Systemverträglichkeit mit dem Grundsatz der Vertragsfreiheit. Nach einer Beleuchtung der kompetenzrechtlichen Dimension der - auf Art. 19 AEUV gestützten - Diskriminierungsverbote setzt er sich eingehend mit dem umstrittenen Problemkreis der Wirkung des Diskriminierungsverbots der Grundrechtecharta der Union auf das Privatrechtsverhältnis auseinander. Abschließend widmet sich Moritz Zoppel den unionsrechtlich gesollten Sanktionen bei verbotener Ungleichbehandlung. Er skizziert dazu die Voraussetzungen eines unionsrechtskonformen Sanktionsinstruments.

Moritz Zoppel Geboren 1986; Studium der Rechstwissenschaften an der Universität Wien und der Universidad Complutense de Madrid; Doktoratsstudium der Rechtswissenschaften an der Universität Wien; Forschungsaufenthalt am Max-PlanckInstitut für ausländisches und internationales Privatrecht in Hamburg; Universitätsassistent am Institut für Zivilrecht der Rechtswissenschaftlichen Fakultät der Universität Wien; Rechtspraktikant im Sprengel des Oberlandesgerichts Wien; derzeit LL.M. Student an der University of Cambridge.

Jetzt bestellen:

https://mohrsiebeck.com/buch/europaeische-diskriminierungsverbote-und-privatrecht-9783161533129?no_cache=1 order@mohrsiebeck.com

Telefon: $+49(0) 7071-923-17$

Telefax: +49 (0)7071-51104 